malnutrition, rejection, and overprotection. The natural reaction of parents of a handicapped child is to do everything for him-feeding him, dressing him-instead of helping him slowly and laboriously to do things for himself. A child with a physical or sensory handicap, a visual or auditory defect, or cerebral palsy is particularly likely to be deprived of the sensory stimulation which a normal child experiences-and so he becomes an underachiever. Attention to these matters-which are the province of all concerned with the management of handicapped children-can do much to help a child towards better fulfilment of his potential. Enrichment programmes should help such children, if only to become more independent. A recent book by a Danish mother of a child with Down's syndrome showed how much a devoted mother can do in this way for a handicapped child. ${ }^{21}$ An enrichment programme should go some way to helping a handicapped child who has been retarded by deleterious socioeconomic factors, a poor home, harmful parental attitudes, understimulation, or neglect to catch up with his peers who have an equal physical or mental handicap without the additional damaging factors which he has experienced. There is now some evidence that some such programmes may have a long-term value.

What must be preserved when assessing the value of remedial treatment for handicapped children is a sense of balance. A highly expensive form of treatment may achieve some benefit, but no more than much simpler measures, and before such costly treatment is started (unless purely for research) we need to know whether its value is temporary or long term.

The possible hazards of treatment must also be consideredfor example, the harm which might be done to the newborn by "bombarding" him with stimuli. ${ }^{1}$ After the newborn period the possible value of intensive treatment for a handicapped child has to be balanced against the adverse effect which might result for the rest, of the family. Finally, if time-consuming, expensive treatment for a severly handicapped child does not achieve the expected beneficial results the parents may be tragically disillusioned and even feel guilty that perhaps all the instructions have not been fully carried out.

Only further, long-term research can point the best way to achieve what we all want-the optimum help for the handicapped to achieve the maximum which their disability and intellectual endowment will permit.

${ }^{1}$ Ferry PC. On growing new neurons: are early intervention programs effective ? Pediatrics $1981 ; 67: 38-41$.

2 Denhoff E. Current status of infant stimulation or enrichment programs for children with developmental disabilities. Pediatrics $1981 ; 67: 32-7$.

3 Browder JA. The pediatrician's orientation to infant stimulation programs. Pediatrics $1981 ; 67: 42-4$.

${ }^{4}$ Bricker D, Carlson L, Schwarz R. A discussion of early intervention for infants with Down's syndrome. Pediatrics $1981 ; 67: 45-6$.

5 Soboloff HR. Development enrichment programs. Dev Med Child Neurol $1979 ; 21: 423-4$.

${ }^{6}$ Kopp CB, Parmelee AH. Prenatal and perinatal influences on infant behavior. In: Osofsky JD, ed. Handbook of infant development. New York: John Wiley, 1979:29-75.

7 Tjossem TD, ed. Intervention strategies for high risk infants and young children. Baltimore: University Park Press, 1976.

8 Hayden AH, Haring NG. Early intervention for high risk infants and young children: programs for Down's syndrome children. In: Tjossem $\mathrm{TD}$, ed. Intervention strategies for high risk infants and young children. Baltimore: University Park Press, 1976:573-607.

9 Piper MC, Pless IB. Early intervention for infants with Down's syndrome. A controlled trial. Pediatrics $1980 ; 65: 463-8$.

10 Beller EK. Early intervention programs. In: Osofsky JD, ed. Handbook of infant development. New York: John Wiley, 1979:852-94.

11 Anonymous. Stimulant drugs for hyperactive children. Drug Ther Bull $1977 ; 15: 22-3$.

${ }^{12}$ Lovell KC, Byrne C, Richardson B. A further study of the educational progress of children who had received special education. $\mathrm{Br} \mathcal{F} E d u c$ Psychol 1963 ;33:3-9.
13 Weinberg WA, Penick EC, Hammerman M, Jackoway M. An evaluation of a summer remedial reading program. A preliminary report on the development of reading. Am f Dis Child $1971 ; 122: 494-8$.

14 Belmont I, Birch HG. The effect of intervention on children with low reading readiness scores. Fournal of Special Education. 1974;8:81-9.

15 Silver LB. Acceptable and controversial approaches to treating the child $\stackrel{\circ}{\circ}$ with learning disabilities. Pediatrics 1975 ;55:406-15

16 Wright T, Nicholson J. Physiotherapy for the spastic child: an evaluation. $\widehat{\Omega}$ Dev Med Child Neurol 1973;15:146-63.

17 Carr J. Young children with Down's syndrome: their developmental upbringing and effects on their families. London: Butterworth, 1975.

18 Dicks-Mireaux MJ. Mental development of infants with Down's syndrome. Am ₹ Ment Defic 1972;77:26-32.

19 Sparrow S, Zigler E. Evaluation of a patterning treatment for retarded children. Pediatrics 1978;62:137-50.

20 Stott DH. Abnormal mothering as a cause of mental subnormality. A $\stackrel{\vec{\sim}}{\rightarrow}$ critique of some classing studies of maternal deprivation in the light of possible congenital factors. F Child Psychol Psychiatry 1962 ;3:79-91.

${ }^{21}$ Bondo U. Ida: life with my handicapped child. London: Faber and Faber, $\overline{\bar{c}}$ 1980 .

\section{No place like home?}

The tide in Britain is running strongly against home deliveries. In 1978 only $1.6 \%$ of births took place in the home as opposed to $13 \%$ in 1970 , and now the House of Commons Social $N$ Services Committee-chaired by Mrs Renée Short-has:recommended that home deliveries should be phased out further. The number of community midwives has fallen from $\infty$ around 4000 in 1972 to about 3000 in 1979, and many of those that remain feel incapable of doing home deliveries. Moreover, $\underset{\omega}{\mathrm{C}}$ many younger general practitioners, who have had only limited obstetric training - and that in hospitals surrounded by equipment and support-are unwilling to supervise home $\vec{\oplus}$ deliveries. In many parts of Britain women who want to give birth at home are faced with the difficult if not impossible task of finding somebody to deliver them. Indeed, this year has seen the prosecution in Scotland of a man who delivered his own wife at home after he had been unable to find a doctor willing to do so.

Why have home deliveries come to be seen as anachronistic ? $\overrightarrow{\overrightarrow{0}}$ The commonly held belief is that they are dangerous. Yet, as Professor Eva Alberman, one of the expert advisers to the Commons Social Services Committee, said recently at a Royal Society of Medicine conference on pregnancy care in the 1980s, in today's circumstances no statistical proof can be produced to support this belief. Indeed, Mrs Margerie Tew, a 3 . statistician from Nottingham, argued (as she had done before) that hospital delivery is more dangerous than home delivery. 3

Clearly most of the delegates were convinced that when 을 selection was careful home births were safe. This has been shown by Dutch experience, which was described by Professor G J Kloosterman, an obstetrician from Amsterdam: a perinatal mortality rate much lower than in Britain and a high (though falling) home-delivery rate have long coexisted in Holland. $N$ Whether home births are a good or a bad thing, however, can $\stackrel{\omega}{\circ}$ never be answered purely by statistical methods-not only because the statistics are inadequate but also because value $\frac{0}{\Phi}$ judgments are so important in this matter.

Should we really mind that home deliveries are fading away? Are the protests just a crusade by a few vocal, middle-class women? Dr Luke Zander, a general practitioner from $\stackrel{\odot}{\mathbb{\Phi}}$ Lambeth, who had arranged the meeting, thought that the $\stackrel{\unrhd}{\varrho}$ issue mattered very much. He thought that it had an importance beyond the small numbers concerned and drew $\delta$ an analogy with capital punishment: just as a society may be judged by its policy on capital punishment so an obstetric 
service could be assessed by its attitude to home deliveries. For the services to oppose home deliveries when they could produce no evidence that they were dangerous was, he implied, an act of professional bullying and boded ill for the relationship between doctors and their patients. If some women want home deliveries then the obstetric services should do their best to provide the necessary facilities.

Free choice was supported by Professor Kloosterman: women with low-risk pregnancies should be able to choose where they wanted their baby delivered. Domiciliary and hospital obstetric services both co-operated and competed in Holland, he said. The competition kept standards high and encouraged the hospital to be as human and non-interventionist as possible, while the co-operation ensured that the domiciliary service was well backed up. The mood of the conference, which contained many more general practitioners and midwives than obstetricians, very much favoured this co-operation. Most delegates could not see why a revitalised domiciliary obstetric service and a humanised hospital service could not work happily together to produce a still lower perinatal mortality rate in Britain-with more women enjoying the experience of childbirth.

The last session of the conference was devoted to a discussion of how pregnancy might be managed over the next decade. Sir John Dewhurst, a past president of the Royal College of Obstetricians and Gynaecologists, thought that all pregnancies would come to be seen as high risk and that all deliveries should take place where all emergencies could be managed efficiently-which presumably means in hospital. Many of the other speakers, however, including Dr Gordon Taylor, a Reading general practitioner, and Dr Zander, believed that home deliveries should be allowed to continue and maybe increase. Both thought that this would need administrative and educational improvements, but that these could be achieved-at relatively little cost and yet with great benefit.

Many obstetricians regard the home-deliveries issue as unimportant. To them the challenge of obstetrics is to reduce the perinatal mortality rate further, particularly in the lower social classes; and the worry of a few-mostly middle-classwomen about where they have their baby is seen as almost an irrelevance. All obstetricians can think of births that have unexpectedly and rapidly become difficult, and the thought of having to manage such births in an ordinary home makes them shudder.

Yet there are some women (and it would be interesting to know how many) who very much want to have their babies at home, and some of them are willing to forgo professional help and break the law if necessary. If home deliveries are to increase again then either declining community obstetric services will have to be resuscitated or, as in the United States, lay midwives will have to be licensed. If people want to reject orthodox medical care, should they be free to do so ? Prosecutions for "illegal" home delivery serve only to highlight the authoritarian image of doctors.

\section{Inhaled foreign bodies}

Inhalation of a foreign body must always be treated as a serious matter, as prompt diagnosis and treatment are essential; it is a not uncommon cause of accidental death in children. ${ }^{1}$

Seeds, nuts, beads, bones, teeth, and many other objects may be inhaled. In Western countries peanuts are major offenders; in Arabic countries the culprits are usually melon seeds. Organic matter tends to cause more problems than inorganic matter, since oils released from a melon seed or peanut (together with salt) may cause additional irritation of the bronchial mucosa. In contrast, if flowering grass heads are inhaled diagnosis may be delayed since these may cause less occlusion and chemical reaction than more solid foreign bodies. A delay in diagnosis may result in bronchiectasis. ${ }^{2}$

Only one-third or so of patients give a history of inhalation. ${ }^{3}$ History taking is important: an episode of choking and coughing or unexplained wheezing or cough should make the doctor suspect a foreign body. Haemoptysis may occur, but the most common clinical manifestations are the triad of cough, wheezing, and decreased air entry. ${ }^{4}$ Foreign bodies are most often found in the right side of the bronchial tree and in the basal bronchi. ${ }^{5}$

As many as two-thirds of patients have abnormal physical signs $^{5}$ such as decreased air entry, rhonchi, or stridor. The incidence of radiological abnormalities has varied widely in reported series. A radio-opaque foreign body is readily recognised, but most foreign bodies are non-opaque. The chest radiograph may be normal, but there are often secondary changes such as obstructive emphysema, atelectasis, pneumonia, or lung abscess. Partial occlusion of a bronchus may cause hyperinflation of the affected lung, and there may be a shift of the heart and mediastinum towards the unaffected side, especially after a forced expiration. Complete occlusion of a bronchus may lead to atelectasis as the trapped air is absorbed. This may be associated with a raised diaphragm and a shift of the mediastinum towards the abnormal side.

Evaluation of a patient with an inhaled foreign body should take account of his age; the nature, location, and size of the inhaled foreign body; and how long it has been in the lung. ${ }^{3}$ Younger patients' air passages are smaller and there is a serious risk from associated oedema. Sharp objects may perforate a bronchus causing a pneumothorax. A hard object may be difficult to grasp with bronchoscopy forceps, and peanuts or flowering grass heads may fragment during removal. In general, the more distal the location of the foreign body the less effect it has on respiration and the less urgent is its removal. Foreign bodies which have been present for a long time may cause abscess formation, atelectasis, or bronchiectasis; their removal may be difficult if they are encased in granulation or fibrous tissue and manipulation may cause bleeding.

Some patients will cough up foreign bodies spontaneously, but in the remainder prompt treatment is indicated. Cotton et $a l^{6}$ advocated treatment by repeated postural coughing and drainage to remove a foreign body, but this may require many repetitions, perhaps without success, and is not now recommended. The safe removal of an inhaled foreign body depends on close co-operation between an experienced anaesthetist and bronchoscopist. Bronchoscopy should be carried out under a general anaesthetic using a rigid bronchoscope with adequate preoxygenation-fibreoptic bronchoscopy is not suitable for this procedure except for a very small peripheral foreign body. Removal of the foreign body may require forceps, suction, and in some cases Dormia baskets, magnets, or Fogarty catheters. ${ }^{7}$ Occasionally more than one bronchoscopy is needed with treatment between operations with postural coughing, physiotherapy, antibiotics, and corticosteroids. Pretreatment with steroids is recommended in all patients under 2 years of age $^{3}$ since these are thought to reduce the degree of oedema of the bronchial mucosa and so make removal of the foreign body easier. Mortality from bronchoscopy procedures for removal of foreign bodies is very low. ${ }^{13-5} 8-12$ 